\title{
Correction to: Moon snails Amauropsis islandica can shape the population of Baltic clams Limecola balthica by size-selective predation in the high-latitude White Sea
}

\author{
Dmitriy Aristov ${ }^{1,2} \cdot$ Marina Varfolomeeva $^{3}$
}

Published online: 3 March 2020

๑) Springer-Verlag GmbH Germany, part of Springer Nature 2020

\section{Correction to: Polar Biology (2019) 42:2227-2236 https://doi.org/10.1007/s00300-019-02597-y}

This correction stands to correct the original article. Due to a proofing oversight the article was published with an error in the Materials and Methods section. Specifically, the rendered, "feeding rate is $1 \pm 0.2 \%$ of pooled living and drilled Limecola" should be replaced with "feeding rate is $21 \pm 3.5 \%$ of pooled living and drilled Limecola". According to the author group, this does not change the Results or Discussion section, but does clarify and correct the previous version. With attention to this, the original article has been corrected.

The original article can be found online at https://doi.org/10.1007/ s00300-019-02597-y.

Dmitriy Aristov

amauropsis@gmail.com

1 Zoological Institute of Russian Academy of Sciences, Saint-Petersburg, Russia

2 Laboratory of Marine Benthic Ecology and Hydrobiology, Saint-Petersburg, Russia

3 Saint-Petersburg State University, Saint-Petersburg, Russia
Publisher's Note Springer Nature remains neutral with regard to jurisdictional claims in published maps and institutional affiliations. 